\title{
Cytochrome P450 2E1 (CYP2E1) regulates the response to oxidative stress and migration of breast cancer cells
}

\author{
Travis Leung ${ }^{1}$, Ramkumar Rajendran', Subir Singh', Richa Garva², Marija Krstic-Demonacos²,3
} and Constantinos Demonacos ${ }^{1 *}$

\begin{abstract}
Introduction: The cytochrome P450 (CYP) enzymes are a class of heme-containing enzymes involved in phase I metabolism of a large number of xenobiotics. The CYP family member CYP2E1 metabolises many xenobiotics and pro-carcinogens, it is not just expressed in the liver but also in many other tissues such as the kidney, the lung, the brain, the gastrointestinal tract and the breast tissue. It is induced in several pathological conditions including cancer, obesity, and type II diabetes implying that this enzyme is implicated in other biological processes beyond its role in phase I metabolism. Despite the detailed description of the role of CYP2E1 in the liver, its functions in other tissues have not been extensively studied. In this study, we investigated the functional significance of CYP2E1 in breast carcinogenesis.
\end{abstract}

Methods: Cellular levels of reactive oxygen species (ROS) were measured by $\mathrm{H}_{2}$ DCFDA (2 2.9.2 2',7'dichlorodihydrofluorescein diacetate) staining and autophagy was assessed by tracing the cellular levels of autophagy markers using western blot assays. The endoplasmic reticulum stress and the unfolded protein response (UPR) were detected by luciferase assays reflecting the splicing of mRNA encoding the $X$-box binding protein 1 (XBP1) transcription factor and cell migration was evaluated using the scratch wound assay. Gene expression was recorded with standard transcription assays including luciferase reporter and chromatin immunoprecipitation.

Results: Ectopic expression of CYP2E1 induced ROS generation, affected autophagy, stimulated endoplasmic reticulum stress and inhibited migration in breast cancer cells with different metastatic potential and p53 status. Furthermore, evidence is presented indicating that CYP2E1 gene expression is under the transcriptional control of the p53 tumor suppressor.

Conclusions: These results support the notion that CYP2E1 exerts an important role in mammary carcinogenesis, provide a potential link between ethanol metabolism and breast cancer and suggest that progression, and metastasis, of advanced stages of breast cancer can be modulated by induction of CYP2E1 activity.

\section{Introduction}

Cytochrome P450 (CYP450) is a superfamily of hemoproteins essential for the biotransformation of drugs [1]. They are mainly localised in the liver, participating in the phase I metabolism of a wide range of exogenous compounds and the biosynthesis and metabolism of endogenous hormones [2]. Apart from the liver, CYPs are also expressed in other tissues such as lung, kidney and

\footnotetext{
* Correspondence: cdemonacos@manchester.ac.uk

${ }^{1}$ School of Pharmacy and Pharmaceutical Sciences, Stopford Building,

University of Manchester, Oxford Road, Manchester M13 9PT, UK

Full list of author information is available at the end of the article
}

hematopoietic tissue [3], and specific isoenzymes of the superfamily have been identified in tumours [4] where they are suggested to affect the response to anticancer therapy $[4,5]$. CYP450s are highly conserved across species implying that, in addition to their function in the metabolism of xenobiotics, these enzymes possibly exert broader physiological functions [6]. Consistent with this view, the CYP2E1 isoenzyme has been implicated in a variety of pathological conditions such as diabetes, nonalcoholic steatohepatitis (NASH) and cancer, possibly as

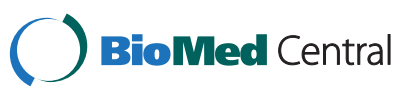

(c) 2013 Leung et al.; licensee BioMed Central Ltd. This is an open access article distributed under the terms of the Creative Commons Attribution License (http://creativecommons.org/licenses/by/2.0), which permits unrestricted use, distribution, and reproduction in any medium, provided the original work is properly cited. 
a result of its capacity to produce high levels of reactive oxygen species (ROS) [7].

CYP2E1 metabolizes several small molecules such as ethanol, acetaminophen and pro-carcinogens like nitrosamines and azo compounds [3]. CYP2E1-mediated metabolism of these compounds generates toxic intermediates and excessive amounts of ROS [7]. High ROS levels, and hence oxidative stress due to increased CYP2E1 protein levels and induced enzymatic activity, are the main causes of various liver diseases associated with chronic alcohol consumption [8] and a variety of other pathophysiological conditions including diabetes type II and obesity [9].

Since CYP2E1 is a key determinant of the cellular redox state generating free radicals in a non-specific manner, even in the absence of a substrate the gene expression of this enzyme is tightly regulated [10]. Indeed, links between CYP2E1 protein levels and cytokines activity have been shown in recent reports [11] as well as variable CYP2E1 gene expression in numerous inflammatory diseases including cancer [12,13]. Autophagy is one of the pathways induced by elevated ROS levels which triggers the accumulation of various autophagyregulated genes (ATGs) including beclin-1 and the light chain 3 (LC3) [14], thereby stimulating the formation of the autophagosome in cancer $[15,16]$.

Furthermore, oxidative stress and other cellular tensions, such as DNA damage and viral infection, impair the protein-folding process resulting in the accumulation of misfolded proteins within the endoplasmic reticulum (ER) lumen [17], stimulating the initiation of the unfolded protein response (UPR) [18]. UPR takes place in the ER lumen and is a major signal transduction pathway aiming to alleviate ER stress by removing accumulated unfolded proteins from this cellular compartment [18].

Clinical studies have indicated that stage I breast tumours express higher CYP2E1 mRNA levels compared to stages II, III and IV [19]. Taken together, the differential expression of CYP2E1 in different tumours and various stages of breast cancer, with its capacity to induce ROS production [7], raises the questions whether CYP2E1 cellular levels could be an indicator of breast cancer progression and which are the factors involved in its differential regulation of gene expression in the various stages of breast cancer. Here we present evidence to suggest that ectopically expressed CYP2E1-mediated oxidative stress regulates autophagy, ER stress and migratory potential and its gene expression is regulated by the p53 tumour suppressor in a cell-type-dependent manner in breast cancer cells.

\section{Methods}

\section{Cell lines, cell culture and constructs}

The human breast carcinoma cell lines MCF7 (p53+/+) [20], T47D (mutated p53) [20], MDA-MB-231 (mutated p53) $[20,21]$ and MDA-MB-157 (p53-/-) [20] (obtained from the European Collection of Cell Cultures (ECACC)) were maintained in Dulbecco's modified Eagle's medium (Sigma-Aldrich, Gillingham, UK), supplemented with 10\% foetal bovine serum (Gibco, Paisley, UK) and 1\% penicillin/streptomycin (Lonza, Allendale, NJ, USA) at $37^{\circ} \mathrm{C}$ in a humidified atmosphere containing $5 \% \mathrm{CO}_{2}$. Cells were treated with $10 \mu \mathrm{M}$ etoposide (Sigma-Aldrich) for 16 hours, $500 \mu \mathrm{M} \mathrm{N}$-acetylcysteine (NAC) (SigmaAldrich) for 16 hours, $2.5 \mathrm{mM}$ acetaminophen (APAP) (Sigma-Aldrich) for $3 \mathrm{~h}, 20 \mu \mathrm{M}$ chlormethiazole (CMZ) (Sigma-Aldrich) for $16 \mathrm{~h}, 1 \mu \mathrm{M}$ bortezomib (Bort) (Selleckchem, Stratech Scientific Ltd., Newmarket, UK) the MCF7 for 24 and the MDA-MB-231 cells for $8 \mathrm{~h}$ and $100 \mathrm{mM}$ ethanol for either 24 or $2 \mathrm{~h}$ as indicated in the figure legends. Transient transfections were carried out using the polyfect transfection reagent (Qiagen, Crawley, UK), according to the manufacturer's instructions. Constructs used for ectopic expression included PCDNA3 [22,23], and $\beta$-galactosidase [22,23]. Human CYP2E1 luciferase reporter containing putative p53 binding sites was constructed by amplifying the upstream region of the CYP2E1 promoter -7873 to -5896 (counted from the translation initiation site) and inserting it in the pGL3 promoter luciferase vector (Promega, Madison, WI, USA). CYP2E1 short hairpin RNA (shRNA) P-silencer was synthesised using the P-silencer 2.1-U6 hygro vector (Agilent Technologies, Wokingham, UK). Dr. Cederbaum (Mount Sinai School of Medicine, New York) kindly provided the CYP2E1 cDNA. The pCAX-HA-2xXBP1 deltaDBD9anATG)-Luc-F luciferase reporter [24] is a generous gift from Dr. Iwawaki (Frontier Research System, Riken, Japan).

\section{Immunoblotting and antibodies}

High-salt lysis buffer $(50 \mathrm{mM}$ Tris- $\mathrm{HCl}$ pH 7.5, $400 \mathrm{mM} \mathrm{NaCl}, 5 \mathrm{mM}$ ethylenediaminetetraacetic acid (EDTA) pH 8, 0.5\% NP-40, 1\% Triton X-100, 1 mM dichlorodiphenyltrichloroethane (DDT), $1 \mathrm{mM}$ phenylmethylsulphonyl fluoride (PMSF) and $1 \mu \mathrm{g} / \mathrm{ml}$ protease inhibitor cocktail (pepstatin, aprotinin, and leupeptin)) was used to harvest cells. After SDS-PAGE and electroblotting membranes were incubated with anti-CYP2E1 (Abcam, Cambridge, UK, ab28146), anti-p53 (Santa Cruz Biotechnology, Santa Cruz, CA, USA, sc-126), anti- $\beta$ actin (Abcam, 8227), anti-LC-3 (Cell Signaling Technologies, Beverly, MA, USA, 4108S), anti-beclin-1 (Cell Signaling Technologies, 3495S), anti-Atg5 (Cell Signaling Technologies, 2630S), anti-Atg7 (Cell Signaling Technologies, 2631S), anti-CCAAT/enhancer-binding protein (C/EBP) homologous protein (CHOP) (Cell Signaling Technologies, 2895S), and anti-GRP78 (Santa Cruz Biotechnology, sc-376768) antibodies. 


\section{2.9.2 2',7'-dichlorodihydrofluorescein diacetate $\left(\mathrm{H}_{2}\right.$ DCFDA) staining}

Cells were transiently transfected with the indicated constructs and $16 \mathrm{~h}$ after transfection dissociated from the plates and centrifuged at 1,200 rpm for 3 mins. Cells were then incubated with $1 \mathrm{ml}$ of APC-H7-conjugated CD20 antibody (BD Biosciences, Franklin Lakes, NJ, USA, 641396) where indicated, washed three times with $\mathrm{PBS}$, incubated with $\mathrm{H}_{2}$ DCFDA (Invitrogen, Carlsbad, CA, USA, D399) in the dark at $37^{\circ} \mathrm{C}$ for $30 \mathrm{~min}$ and subjected to fluorescence-activated cell sorting (FACS) analysis using CYAN-ADP flow cytometer (Dako, Glostrup, Denmark) following the fluorescence profile of 2 2.9.2 $2^{\prime}, 7^{\prime}$-dichlorodihydrofluorescein diacetate ( $\left.\mathrm{H}_{2} \mathrm{DCFDA}\right)$ and $\mathrm{APC}-\mathrm{H} 7$ probes.

\section{Chromatin immunoprecipitation}

The process for chromatin immunoprecipitation (ChIP) has been described in the past $[22,23]$. Briefly chromatin was cross-linked with $1.42 \%$ formaldehyde and crosslinking was quenched by addition of $125 \mathrm{mM}$ glycine. Cells were then harvested in IP buffer $(50 \mathrm{mM}$ Tris- $\mathrm{HCl}$ pH 7.5, $150 \mathrm{mM} \mathrm{NaCl} 5$ mM EDTA pH 8, 0.5\% NP-40, $1 \%$ Triton X-100, $1 \mathrm{mM}$ DDT, $1 \mathrm{mM}$ PMSF, $1 \mu \mathrm{g} / \mathrm{ml}$ protease inhibitor cocktail (pepstatin, aprotinin, and leupeptin), $20 \mathrm{mM} \beta$-glycerol phosphate, and $2 \mathrm{mM}$ sodium orthovanadate). Chromatin was sheared by sonication (Bioruptor, Denville, NJ, USA) and subjected to immunoprecipitation with the indicated antibodies. Precipitated DNA fragments were then amplified in PCR reactions with specific primers ( $F$ ' GAGGAGAGG CAAGTTTG and R' AGTCCCTTCGCCTGTTTCTT) flanking the putative p53 binding sites identified within the CYP2E1 promoter and analysed by agarose gel electrophoresis.

\section{UPR study using PCAX-HA-2xXBP1deltaDBD9anATG)- Luc-F construct}

The principle of the pCAX-HA-2xXBP1deltaDBD9anATG)Luc-F function has been described by Iwawaki and Akai [24]. In brief, stimulation of the ER stress in cells upregulates UPR by activating the ER signalling proteins PKR-like endoplasmic reticulum kinase (PERK), activating transcription factor 6 (ATF6) and inositol-requiring enzyme 1 (IRE1). Upon activation, the endoribonuclease activity of IRE1 catalyses splicing and removal of an intron from the Xbox binding protein 1 (XBP1) encoding mRNA thereby allowing its translation into a functional transcription factor [18]. Initiation of UPR and activation of XBP1 induces luciferase production from the pCAXHA-2xXBP1deltaDBD9anATG)-Luc-F reporter whereas in the absence of UPR the inactive XBP1 is unable to stimulate luciferase production [24].

\section{Scratch wound cell migration assay}

The scratch wound assay was performed as described previously [25]. Briefly coverslips were placed in 6-well plates and an insert (ibidi, Munich, Germany) was placed onto the coverslip before cells were seeded. After ibidi chambers adhered onto the coverslips, $3 \times 10^{4}$ of MCF7, $3 \times 10^{4}$ of MDA-MB-231 and $6 \times 10^{4}$ of MDAMB-157 cells were seeded into each side of the chamber and incubated overnight at $37^{\circ} \mathrm{C}$ to subclonfluent stage and then transiently transfected or treated with different drugs as indicated. The inserts were then removed from the coverslips, $2 \mathrm{ml}$ of cell culture medium was added and cells were incubated at $37^{\circ} \mathrm{C}$ to allow cell migration for $16 \mathrm{~h}$ for MCF7 and MDA-MB-157, and $8 \mathrm{~h}$ for MDA-MB-231 cells. Subsequent to cell migration, cells were fixed with $4 \%$ paraformaldehyde in PBS for $30 \mathrm{~min}$ at room temperature. After cell fixation, cells were washed three times with PBS and permeabilised with Triton (X-100). Anti- $\beta$-actin antibody (Abcam, ab8227) and 4',6-diamidino-2-phenylindole (DAPI) (Sigma-Aldrich, F6057) were used to stain cells.

No patients' cells/tissues or animals were used in this study therefore there was no need for ethical approval.

\section{Statistical analysis}

Statistical analysis of differences was carried out using Student's $t$ test, one-way analysis of variance (ANOVA) and Tukey's post hoc test. Values $P<0.05$ are indicated with two asterisks and $P<0.01$ with three asterisks.

\section{Results}

\section{CYP2E1 contributes to ROS generation in breast cancer} cells

It has been shown that CYP2E1 is one of the most active CYP450 isoforms in generating intracellular ROS [26] and oxygen radicals are associated with cancer development and metastasis [27]. Several observations link CYP2E1 with inflammatory reactions and carcinogenesis in different tissues [28,29] suggesting that CYP2E1 might be involved in the regulation of tumour growth [29]. To investigate the role of CYP2E1 in breast cancer, ROS generation was monitored in MCF7, and MDA-MB-157 cells treated with ethanol, which is a known CYP2E1 inducer. In addition, ROS levels were monitored in MCF7, MDAMB-231 and MDA-MB-157 cells treated with either the topoisomerase II inhibitor etoposide, which induces the transcriptional activity of transcription factors such as p53 and NRF2 which could potentially be involved in the regulation of CYP2E1 gene expression [30,31], the antioxidant NAC or ectopically expressing CYP2E1.

Elevated intracellular ROS levels were observed in ethanol-treated MCF7 and MDA-MB-157 cells (Figure 1A, compare bar 3 to bar 1 and bar 4 to bar 2 respectively). Increased ROS levels were also recorded in MCF7 and 

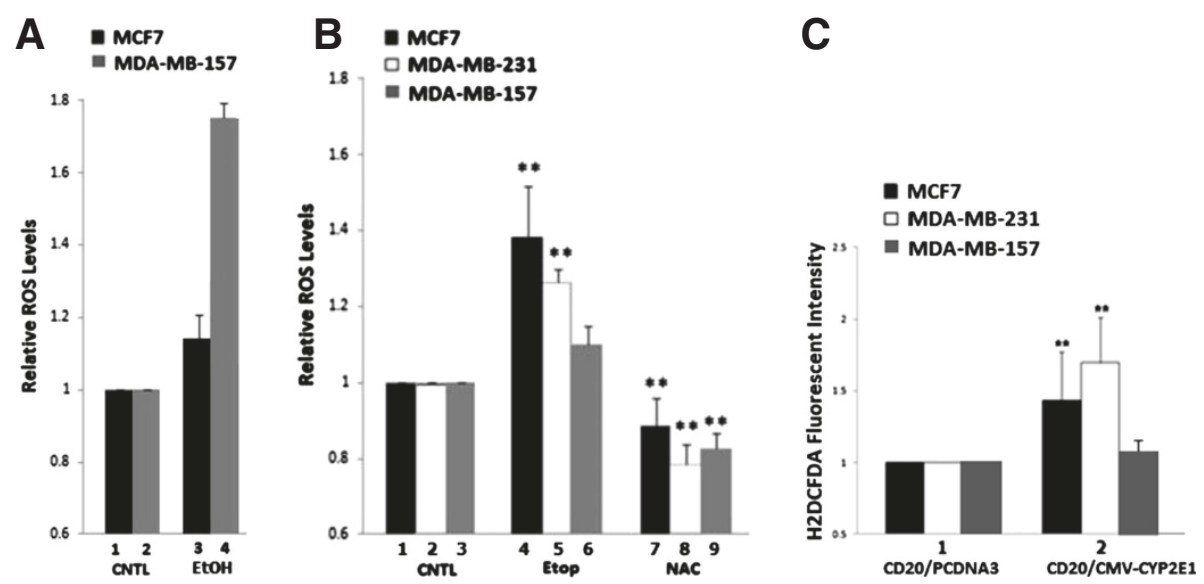

Figure 1 Ectopic expression of CYP2E1 induces ROS generation in breast cancer cells. (A) MCF7 and MDA-MB-157 cells were treated with ethanol and ROS levels were estimated using $\mathrm{H}_{2}$ DCFDA and FACS analysis. (B) MCF7, MDA-MB-231 and MDA-MB-157 cells were treated with etoposide and NAC and ROS levels were estimated as in (A). (C) MCF7, MDA-MB-231 and MDA-MB-157 cells were co-transfected with CD20 and either PCDNA3 or CMV-CYP2E1 expression plasmid. Subsequent to transfection, cells were treated with $\mathrm{H}_{2} \mathrm{DCFDA}$ fluorescent stain, and transfected cells were sorted with an APC-conjugated anti-CD20 antibody and FACS analysis. Data represent fold induction of ROS levels. Error bars indicate standard deviation obtained from three independent experiments performed in duplicates. Asterisks indicate significant difference at $P<0.05$. CYP2E1, cytochrome P450 E1; FACS, fluorescence-activated cell sorting; $\mathrm{H}_{2}$ DCFDA, 2 2.9.2 2',7'-dichlorodihydrofluorescein diacetate; NAC,

$\mathrm{N}$-acetylcysteine; ROS, reactive oxygen species.

MDA-MB-231 cells treated with etoposide (Figure 1B, compare bar 4 to bar 1 and bar 5 to bar 2 respectively). Moderate increase of ROS levels was observed in MDAMB-157 cells treated with etoposide (Figure 1B, compare bar 6 to bar 3). Decreased ROS levels were identified in MCF7, MDA-MB-231 and MDA-MB-157 cells treated with the antioxidant reagent NAC (Figure 1B, compare bars 7, 8 and 9 to bars 1,2 and 3 respectively). Increased intracellular ROS levels were also detected in MCF7 and MDA-MB-231 cells overexpressing CYP2E1 (Figure 1C, compare black and white bars 2 to black and white bars 1 respectively). Overexpression of CYP2E1 did not significantly affect the ROS levels in the MBA-MD-157 cells (Figure 1C, compare grey bar 2 to grey bar 1 ).

ROS levels detected by FACS analysis in MCF7, MDAMB-231 and MDA-MB-157 cells were a result of CYP2E1 ectopic overexpression as cells transiently transfected with CYP2E1 expression vector were selected by CD20 cotransfection as described in the Materials and methods.

\section{Role of CYP2E1 in autophagy}

To shed light on the role of the CYP2E1-mediated ROS generation in breast cancer $[14,15]$ the levels of the autophagic markers beclin-1, LC3, Atg5 and Atg7 were monitored in MCF7 and MDA-MB-231 breast cancer cells transiently transfected with CYP2E1 expression vector or shRNA to silence the CYP2E1 expression.

CYP2E1 ectopic expression in MCF7 cells shown in Figure 2A (compare lane 2 to lane 1 ) and CYP2E1 silencing by CYP2E1 shRNA (Figure 2A, compare lane 4 to lanes 1 and 3) did not have any significant effect on beclin-1, LC3-2/LC3-1 ratio, Atg5 and Atg7 protein levels in these cells (Figure 2A, compare lane 2 to lanes 1 and 3). On the other hand increased beclin-1, LC3-2/LC3-1 ratio, Atg5 and Atg7 protein levels coincided with CYP2E1 ectopic expression in MDA-MB-231 cells (Figure 2B, compare lane 2 to lanes 1 and 3). Reduced protein levels of these autophagy markers were observed in MDA-MB-231 cells transfected with shRNA against CYP2E1 (Figure 2B, compare lane 4 to lanes 1 and 3). Western blot analysis of the autophagic markers in MDA-MB-231 cells lent support to the notion that autophagy is regulated by CYP2E1 in MDA-MB-231 breast cancer cells.

\section{Role of CYP2E1 in the regulation of the endoplasmic reticulum stress}

Recently published observations have indicated that CYP2E1 is mainly localised within the endoplasmic reticulum and functions as metabolic enzyme by oxidising xenobiotics [32]. Due to their highly reactive properties, ROS have a short half-life and limited diffusion distance [33], therefore, they usually inflict cellular damage and impact molecular pathways only near the site of their production [34]. It is well known that generation of ROS, sensitisation of ER and initiation of the unfolded protein response [35] and autophagy are closely related processes [36,37]. Taken together all the above information triggered our interest to explore the potential involvement of CYP2E1 in the regulation of ER stress.

The CYP2E1-mediated ER stress and UPR were assessed in breast cancer cells by monitoring the luciferase activity of the pCAX-HA-2xXBP1deltaDBD9anATG)- 


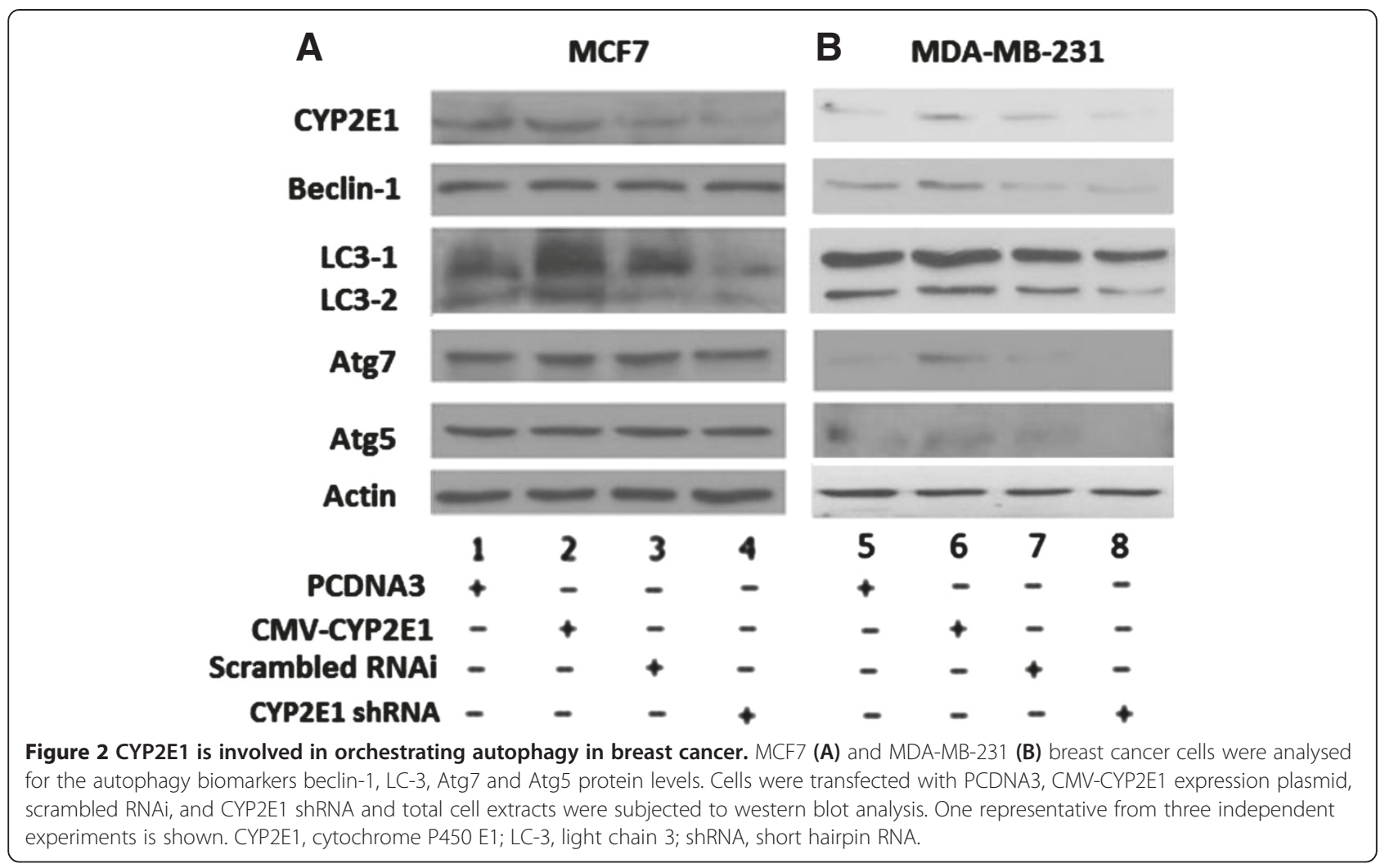

Luc-F reporter in breast cancer cell lines transfected with PCDNA3, CYP2E1, scrambled RNAi, or CYP2E1 shRNA. Increased XBP1 splicing was observed in MCF7 cells overexpressing CYP2E1 (Figure 3A, compare bar 2 to bar 1) whereas silencing of CYP2E1 expression by CYP2E1 shRNA transfection resulted in pCAX-HA-2xXBP1delta DBD9anATG)-Luc-F activity similar to that exhibited by the cells transfected with empty vector or scrambled RNAi (Figure 3A, compare bar 4 with bars 1 and 3). MDA-MB231 cells overexpressing CYP2E1 on the other hand, displayed a slight not significant increase of XBP1 splicing (Figure 3B, compare bar 2 to bar 1) [24]. Evaluation of the ER stress markers CHOP and GRP78 indicated increased levels of these proteins in the MCF7 cells transfected with CYP2E1 expression vector compared to MCF7 cells in which CYP2E1 expression had been silenced (Figure 3C, compare lane 2 to lanes 1 and 3 and lane 4 to lanes 1 and 3 respectively). No changes of $\mathrm{CHOP}$ and glucoseregulated protein 78 (GRP78) protein levels were observed in MDA-MB-231 cells (Figure 3C, lanes 5 to 8 ).

\section{CYP2E1 modulates cell migration potential}

Results shown in Figure 1 provide evidence that CYP2E1 is a potential regulator of intracellular ROS levels in breast cancer cells. The link between oxidative stress and metastasis has been demonstrated in several recent publications $[38,39]$. Taken together the role of CYP2E1 in inducing ROS generation and the fact that CYP2E1 is differentially expressed in early rather than later stages of breast cancer [19] implies that this cytochrome P450 isoenzyme might regulate migration of breast cancer cells. To understand the role of CYP2E1 in these processes, the low invasive MCF7 and the highly invasive MDA-MB-231 as well as the MDA-MB-157 breast cancer cells were transiently transfected with CYP2E1 expressing constructs or vectors silencing the expression of this enzyme and cell migration was analysed employing the scratch wound assay.

MCF7 cells overexpressing CYP2E1 displayed reduced migration capacity compared to those transfected with the empty vector (Figure 4A and B compare bar 1 to bar 4). On the other hand, MCF7 cells in which CYP2E1 had been silenced exhibited increased cell migration compared to MCF7 cells transfected with PCDNA3 (Figure 4A and B compare bar 1 to bar 7). Increased migration capacity was also observed in MDA-MB-231 cells in which CYP2E1 had been silenced (Figure 4A and B compare bar 2 to bar 8). CYP2E1 overexpression had marginal effect on the ability of MDA-MB-231 cells to migrate (Figure 4A and $B$ compare bar 2 to bar 5). Overexpression or silencing of CYP2E1 in MDA-MB-157 cells did not change significantly the ability of these cells to migrate compared to those transfected with PCDNA3 (Figure 4A and B compare bar 3 to bars 6 and 9). 

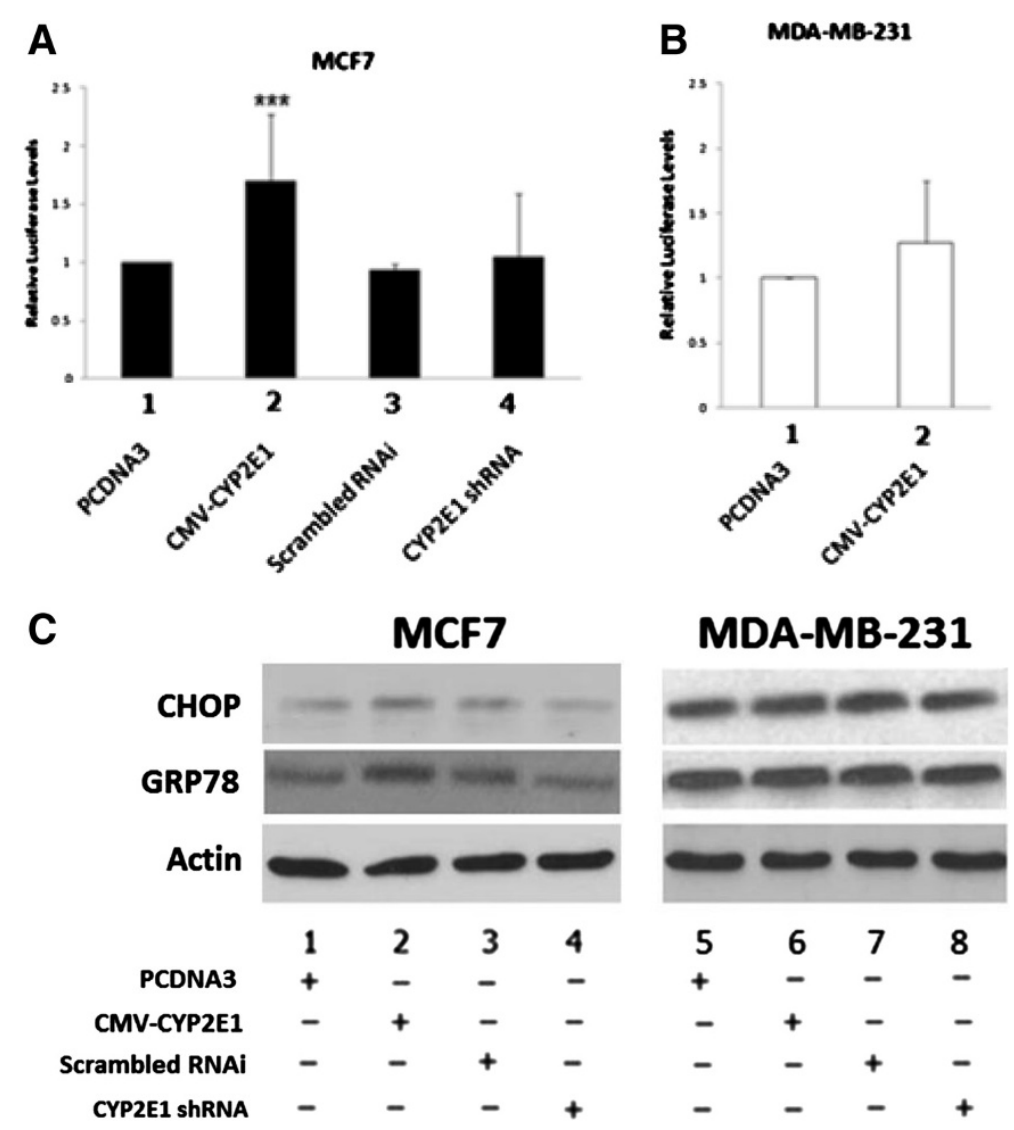

Figure 3 ER stress is induced in MCF-7 and MDA-MB-231 breast cancer cells ectopically expressing CYP2E1. (A) MCF7 and (B) MDA-MB231 breast cancer cell lines were transfected with ERAI-Luc and indicated constructs. Cells were harvested and luciferase activity was measured. Luciferase readings were normalized to the $\beta$-galactosidase. Data are representative of three independent experiments. Error bars represent standard deviation. (C) MCF7 and MDA-MB-231 breast cancer cell lines were transfected with the indicated constructs and submitted to western blot analysis for the ER stress markers CHOP and GRP78. One representative from three independent experiments is shown. CHOP, CAATienhancerbinding protein homologous protein; CYP2E1, cytochrome P450 E1; ER, endoplasmic reticulum; GRP78, glucose-regulated protein 78.

To further investigate the molecular mechanisms by which CYP2E1 gene expression affects cell migration in breast cancer cells, the migration capacity of untreated, ethanol, Bort, APAP [40] and the CYP2E1-specific inhibitor CMZ-treated [41] MCF7 and MDA-MB-231 cells was monitored. Ethanol induces CYP2E1 enzymatic activity, and Bort is a proteasome inhibitor that has been shown to induce response to ER stress by stimulating the accumulation of misfolded proteins in the ER [42]. In accord with results shown in Figure 4, decreased cell migration was observed in ethanol-treated MCF7 cells whereas induction of CYP2E1 by ethanol in MDA-MB231 cells marginally decreased cell migration (Figure 5B, compare bar 3 to bar 1 and bar 4 to bar 2 respectively). Decreased cell migration was observed in APAP- and Bort-treated MCF7 and MDA-MB-231 compared to non-treated cells (Figure 5D, compare bars 3 and 5 to bar 1 and bars 4 and 6 to bar 2). This effect was not evident in MCF7 and MDA-MB-231 cells treated with CMZ compared to non-treated cells (Figure 5D, compare bars 7 and 8 to bars 1 and 2 respectively). Results presented in Figures 4 and 5 revealed that induction of CYP2E1 reduced the migration capacity whereas silencing of this CYP450 isoenzyme increased the number of MCF7 and MDA-MB-231 cells migrating within the gap indicating that CYP2E1 is potentially involved in the regulation of the migratory capacity of breast cancer cells.

\section{CYP2E1 gene expression is under p53 transcriptional control}

The molecular mechanism underlying CYP2E1 induction has not been clearly elucidated but seems to involve messenger RNA or protein stabilization and/or transcriptional activation [43]. Taking into account the fact that the high levels of ROS produced in cells due to the function of this enzyme could stimulate the transcriptional activity of the cancer-related transcription factor p53 [44] as well as that decreased CYP2E1 levels observed throughout cancer progression in different 

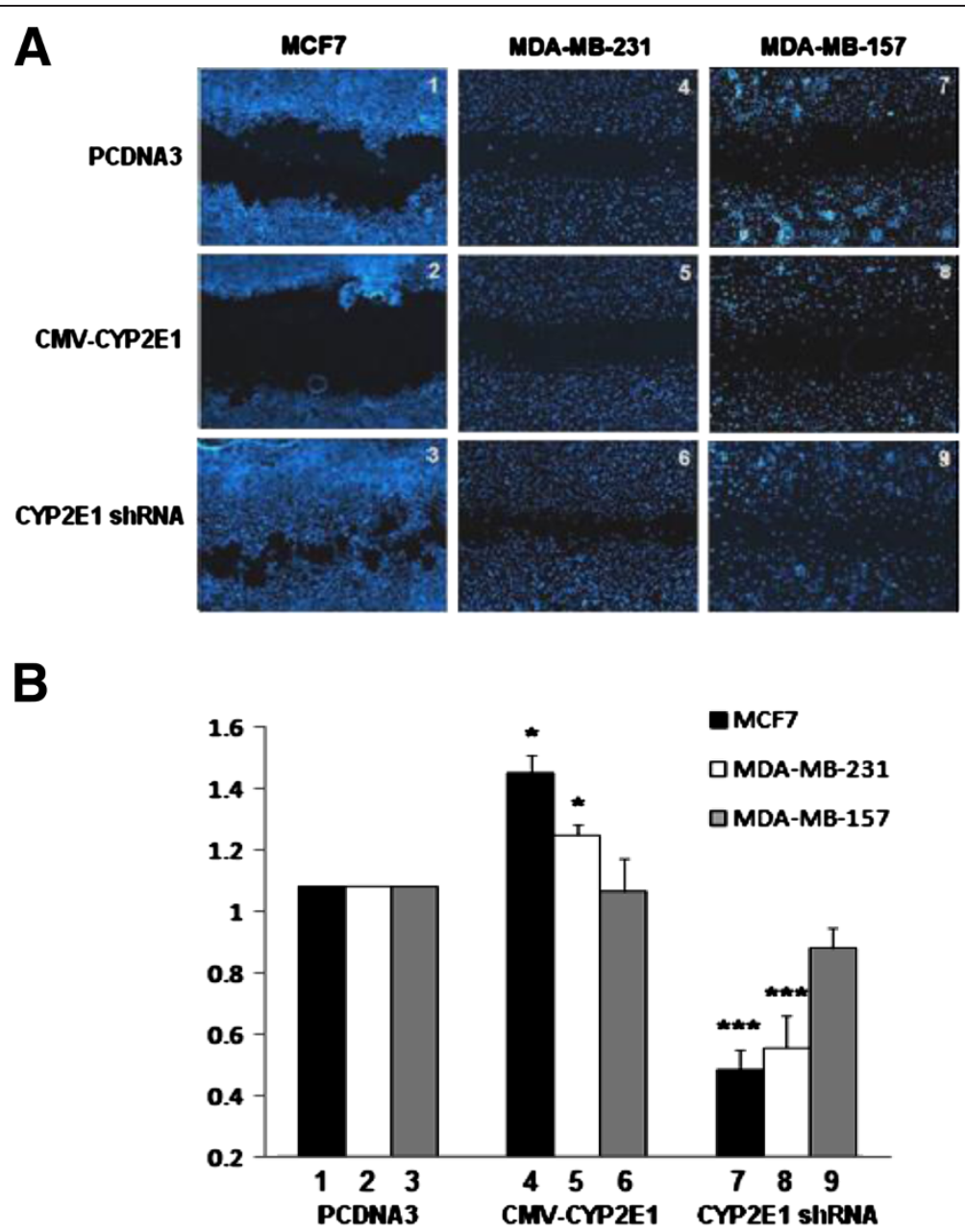

Figure 4 Ectopic expression of CYP2E1 regulates migration of breast cancer cells. (A) MCF7, MDA-MB-231 and MDA-MB-157 cells were seeded and incubated with an ibidi culture insert until they reached subconfluent state and then transfected with PCDNA3, CMV-CYP2E1 or CYP2E1 shRNA plasmids and incubated for further $16 \mathrm{~h}$. The size of the gap was measured after $16 \mathrm{~h}$ (MCF7, MDA-MB-157) and $8 \mathrm{~h}$ (MDA-MB231). (B) Figure represents the calculations of migration distances of cells in (A). Asterisks indicate significant difference at $P<0.01$. CYP2E1, cytochrome P450 E1; shRNA, short hairpin rRNA.

cancers $[19,45]$ led us to explore the possibility that CYP2E1 was a possible p53 transcriptional target.

To test the hypothesis whether higher CYP2E1 cellular levels in stage I breast tumors compared to stages II, III, and IV were a result of differential transcriptional regulation of its gene expression and potential involvement of p53 [46] in this process, we followed the CYP2E1 protein levels in five different breast cancer cells with different migratory potential and p53 status, namely MCF7 [20], T47D [20], MDA-MB-231 [21], MDA-MB-468 and MDAMB-157 [20] exposed to either ethanol (MCF7, MDAMB-231and MDA-MB-468) or etoposide (etop) (MCF7, MDA-MB-231, T47D and MDA-MB-157) treatment.

Accumulation of CYP2E1 protein was observed in response to ethanol in MCF7, MDA-MB-231 and MDAMB-468 cells (Figure 6A, compare lanes 2, 4 and 6 to lanes 1, 3 and 5 respectively) whereas in response to etoposide treatment increased CYP2E1 protein levels were evident in MCF7 and MDA-MB-231 cells (Figure 6B, compare lanes 2 and 4 to lanes 1 and 3 respectively) and no significant changes in T47D and MDA-MB-157 cells (Figure 6B, compare lanes 6 and 8 to lanes 5 and 7 respectively). Reasons explaining the lack of correlation between the CYP2E1 and p53 protein levels in all cell lines could be that p53 is not the only transcription factor that mediates CYP2E1 gene expression and that p53 might be stabilised and accumulated in MDA-MB-231 and T47D cells but it is transcriptionally inactive.

To gain further insight in the transcriptional regulation of the CYP2E1 gene expression and investigate the potential role of p53 in the regulation of the cellular levels of this enzyme the luciferase activity of the 

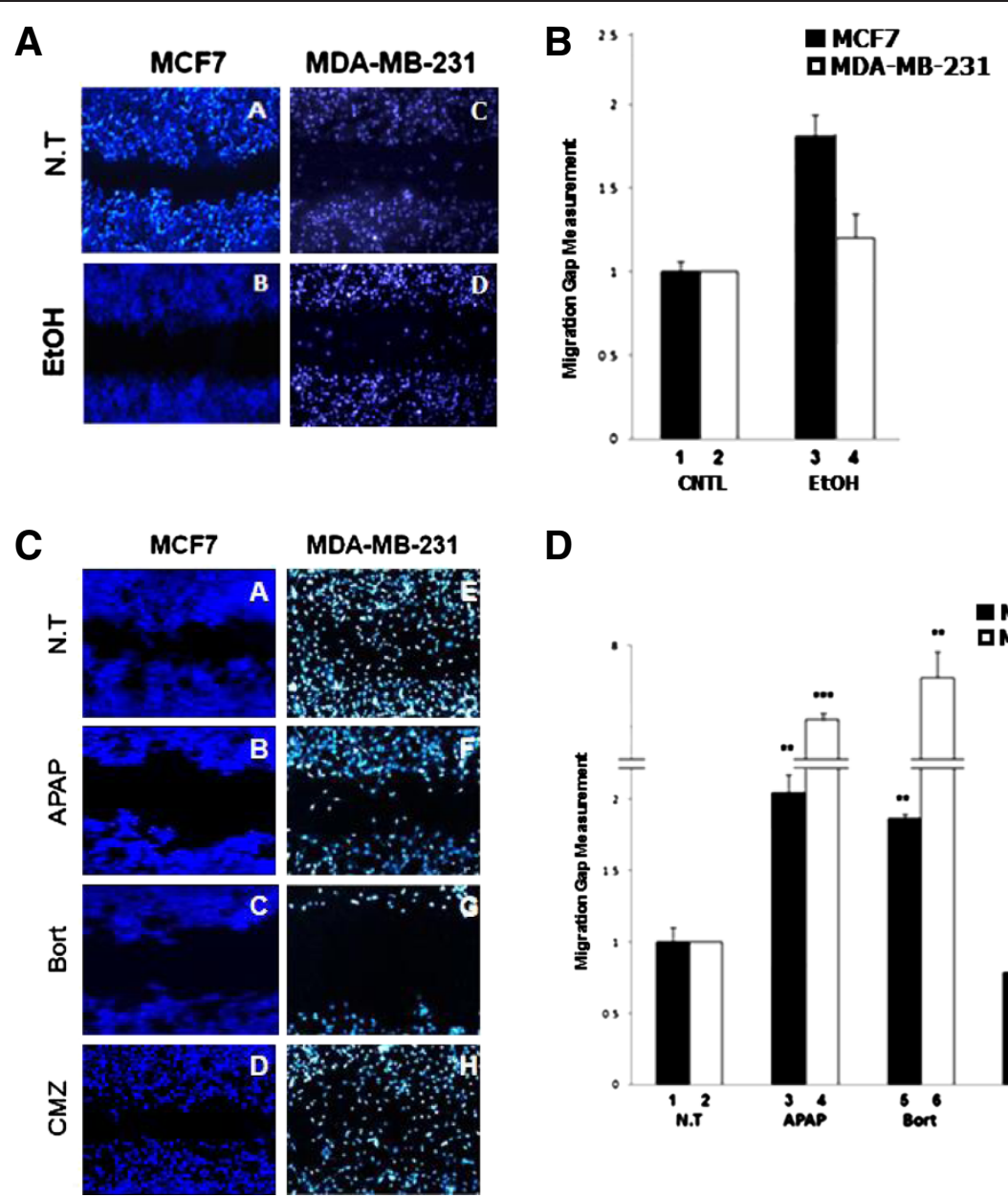

D

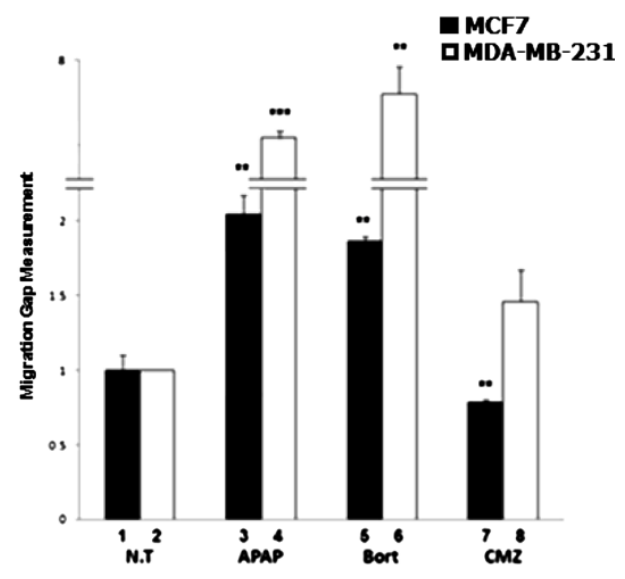

Figure 5 CYP2E1 regulates cell migration in breast cancer cell lines. (A) MCF7 and MDA-MB-231 cells were seeded and incubated with an ibidi culture insert up to subconfluent stage. Cell migration was estimated $16 \mathrm{~h}$ (MCF7) and $3 \mathrm{~h}$ (MDA-MB-231) after the addition of ethanol. (B) Figure represents the calculations of migration distances of cells in (A). (C) MCF7 and MDA-MB-231 cells were seeded and incubated as described in (A). Cell migration was estimated $3 \mathrm{~h}$ after the addition of acetaminophen (APAP), $24 \mathrm{~h}$ (MCF7) and $8 \mathrm{~h}$ (MDA-MB-231) after the addition of bortezomib (Bort) and $16 \mathrm{~h}$ after the addition of chlormethiazole (CMZ). (D) Figure represents the calculations of migration distances of cells in (C). Asterisks indicate significant difference at $P<0.05$ (2) and $P<0.01$ (3). CYP2E1, cytochrome P450 E1.

CYP2E1-Luc reporter containing the putative p53 binding sites [44] identified in the regulatory region of the promoter of this gene was studied in MCF-7 breast cancer cells. Gradual increase of ectopic expression of p53 resulted in upregulated CYP2E1-Luc reporter activity (Figure 6C, compare bars 2, 3 and 4 to bar 1). The p53 protein levels were analysed to confirm its ectopic overexpression (Figure 6B, compare lanes 2, 3 and 4 to lane 1). Furthermore, to confirm whether the putative p53 binding sites were functional, the recruitment of p53 to these putative binding sites was followed in control or treated with etoposide MCF7 breast cancer cells using ChIP assay. Increased occupancy of the CYP2E1 promoter by p53 in the etoposide-treated compared to the non-treated cells was observed (Figure 6D, compare lane 2 to lane 1 ) implying that p53 is possibly involved in the regulation of CYP2E1 gene expression.

\section{Discussion}

CYP2E1 is a drug-metabolising enzyme primarily expressed in hepatocytes, but has also been detected in other tissues including breast, brain, kidney and lungs [3]. CYP2E1 metabolises several pro-carcinogens including ethanol [7] and, for that reason, most of the research associated with CYP2E1 focuses on its role in liver diseases [8]. However, its functions in other tissues have not been extensively studied.

Clinical studies have indicated higher CYP2E1 gene expression in breast tumours than normal tissues [47] and decreasing CYP2E1 levels as carcinogenesis progresses [19] suggesting that this enzyme might serve important functions in breast carcinogenesis. Given that CYP2E1 is one of the most active ROS-generating CYP450 isoforms [7] and considering the link between oxidative stress and tumour growth we hypothesised that 


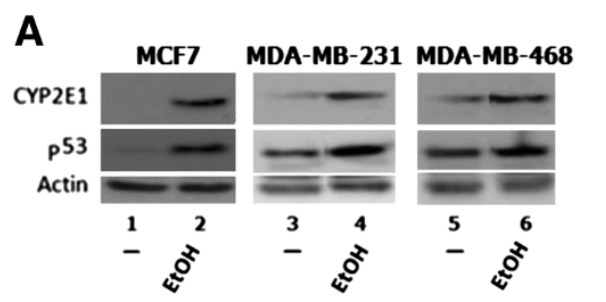

C

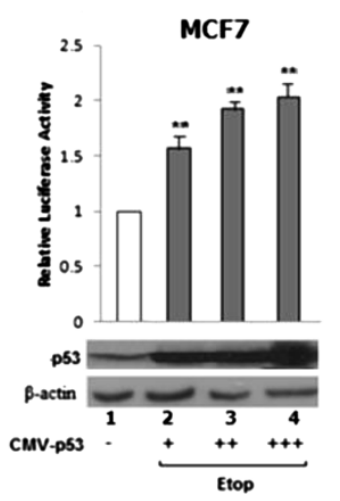

B

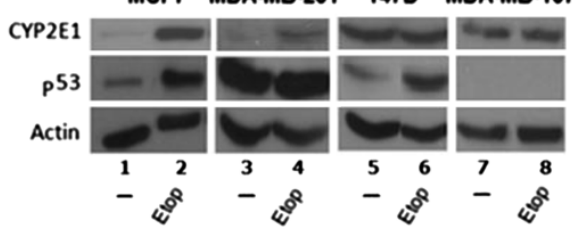

D

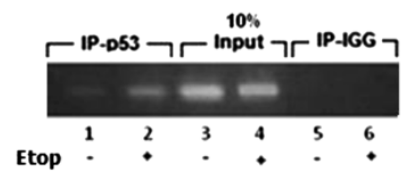

Figure 6 CYP2E1 gene expression is under the transcriptional control of p53. (A) Breast cancer cell lines MCF7, MDA-MB-231, and MDAMB-468 were treated with ethanol and cellular extracts were submitted to western blot analysis with anti-CYP2E1, anti-p53, and anti- $\beta$-actin antibodies. (B) MCF7, MDA-MB-231, T47D and MDA-MB-157 cells were treated with etoposide and total cellular extracts were subjected to western blot analysis as for (A). (C) CYP2E1-Luc reporter assay in MCF7 cells transfected with increasing amounts of CMV-p53. Data presented as fold induction of luciferase activity in cells. Results represent the average of three independent experiments. (D) Chromatin immuniprecipitated using specific p53 monoclonal antibody in non-treated or etoposide-treated MCF7 cells. The pulled-down DNA samples were amplified with PCR primers targeting CYP2E1 promoter. The resultant PCR product was then submitted to 1\% agarose gel electrophoresis and visualised by UV light. CYP2E1, cytochrome P450 E1.

CYP2E1-mediated ROS generation could regulate breast carcinogenesis.

In agreement with published observations [7], we detected increased intracellular ROS levels in breast cancer cells overexpressing CYP2E1 in a manner dependent on the status of p53. The p53 tumour suppressor plays an important role in the regulation of the cellular ROS generation and, in turn, ROS exert positive and negative effects on the p53 protein stability, transcriptional activity and gene target selectivity [46]. Low amounts of ROS correlate with stimulation of the expression of anti-oxidant p53 target genes (glutathione peroxidase 1 (GPX1) [48], aldehyde dehydrogenase 4 (ALDH4) [49], sestrins 1 and 2 (SESN1 and 2) [50]) and genes involved in the cellular energy metabolism such as $\mathrm{SCO} 2$ (synthesis of cytochrome c oxidase 2) [51], TIGAR (TP53-induced glycolysis and apoptosis regulator) [52] and PGM (phosphoglycerate mutase) [53]. The pro-oxidant effects of p53 are mediated by another set of its target genes such as the p53-induced gene 3 (PIG3) [54] the p66Shc [55] and the Bcl2 family members bax and PUMA $[50,56]$. The mechanisms directing the p53 target selectivity to antioxidant or pro-oxidant transcriptional target genes, thereby determining the final outcome of the p53-mediated cellular redox state, include posttranslational modifications and recognition of specific
DNA binding sites in the regulatory regions of the promoters of pro-oxidant subsets of genes by domains different than the p53 DNA binding domain (proline-rich domain) $[50,54,57]$ and the affinity of p53 binding to the promoter of its diverse transcriptional targets follows a hierarchical order that is dependent on the type of stress [22,58,59]. In these terms, the amount of CYP2E1-mediated ROS generation could induce either antioxidant or pro-oxidant p53 outcomes in a tissue and cell-type-dependent manner.

Since intracellular ROS levels are closely linked to the regulation of autophagy, we followed the autophagy biomarkers beclin-1, LC-3, Atg7 and Atg5 protein levels in breast cancer cells in which the CYP2E1 was either ectopically expressed or silenced. In line with potential tumour-suppressing function of autophagy, we identified that the protein levels of the autophagy markers $[60,61]$, followed the same pattern as that of CYP2E1 in MDAMB-231 cells. The role of p53 in linking cellular redox status energy metabolism and autophagy through transcription independent and transcription dependent mechanisms has been extensively investigated [62-64].

Taking into account the fact that CYP2E1 is predominantly localized in the endoplasmic reticulum [65] as well as the link between autophagy and ER stress [36,37] 
we investigated the possibility that CYP2E1 was part of the ER stress signalling transduction pathway. Integrated regulation of autophagy, ER stress and unfolded protein response determines the cell fate in breast cancer [61]. ER stress is able to both inhibit and activate the p53 pathway $[66,67]$. ER stress in MCF-7 cells stimulates p53 nuclear localization, transcriptional activity and protein stability through the NF- $\mathrm{BB}$ signalling pathway [68]. In accord with published evidence indicating that CYP2E1 is a positive regulator of UPR [21], our results lent support to the notion that CYP2E1 induces UPR in MCF7 breast cancer cells transfected with CYP2E1. UPR is altered in many types of cancer [69], including breast cancer, and in some cases contributes to chemoresistance $[24,35,70,71]$, highlighting the importance of our findings for cancer therapy.

The decreasing levels of CYP2E1 in advanced stages of breast cancer cells [19] together with our observations indicating that high cellular levels of CYP2E1 induce autophagy in MDA-MB-231 cells and UPR in MCF7 cells, both of which are regulators of the tumour microenvironment [61], led us to investigate its role in regulating migration of breast cancer cells. To address this question, migration was followed in breast cancer cells expressing different levels of CYP2E1. Our results provided evidence that CYP2E1 expression in breast cancer cells plays a role in the determination of migratory capacity. In particular, CYP2E1 ectopic expression inhibited MCF7 and MDAMB-231 cell migration whereas CYP2E1 silencing or inhibition of its enzymatic activity promoted the ability of these cells to migrate. Differences in the p53 status between MDA-MB-231 and MDA-MB-157 cells, as well as potential defects in the phosphorylation events stabilising microtubule-associated proteins in a manner involving CYP2E1-mediated ROS, could explain the difference in terms of metastasis in the two cell lines. Cytoskeletal alterations mediated by microtubule-associated proteins such as members of the tubulin family [72] and the microtubule-associated protein Tau [73] play an important role in breast cancer cells' metastasis and their cellular levels are affected by p53 [72] and the estrogen receptor $[74,75]$ status. Another possible mechanism explaining the effects of the p53-CYP2E1-ROS generation axis on cell invasion and metastasis could be mediated by heparanase, which is a p53 transcriptional target [76] and is involved in the regulation of the ER stress-mediated breast cancer cell migration [77], but this hypothesis requires experimental validation.

To investigate the factors regulating CYP2E1 gene expression, its protein levels were followed in breast cancer cells with different p53 and estrogen receptor status treated with either ethanol, which induces CYP2E1 enzymatic activity, or the topoisomerase II inhibitor etoposide, which induces DNA damage and activates p53 response. Our results strengthened the hypothesis that p53 is a possible upstream regulator of CYP2E1 gene expression.

Taken together, the results presented in this manuscript provide evidence to suggest that CYP2E1 plays an important role in breast carcinogenesis and the extent of the oxidative stress mediated by CYP2E1 determines distinct p53-mediated effects on autophagy, ER stress and metastasis in breast cancer cells. Since CYP2E1 overexpression restrains migration in the invasive MDA-MB-231 cells, manipulation of CYP2E1 cellular levels could potentially be beneficial for better outcome of late stages of breast cancer. In addition, since this enzyme is involved in the metabolism of alcohol, observations described in this manuscript could be an additional link between chronic alcohol consumption and breast cancer [78,79].

\section{Conclusions}

Ectopic expression of CYP2E1 in breast cancer cells increase ROS generation, modulates autophagy and regulates ER stress and unfolded protein response in a cell-typedependent manner. In addition, induction of CYP2E1 gene expression is under the transcriptional control of the p53 tumor suppressor and its activation inhibits migration of the highly invasive MDA-MB-231 breast cancer cells. The results shown in this manuscript suggest that manipulation of CYP2E1 protein levels and enzymatic activity could be potentially exploited in breast cancer therapy.

\section{Abbreviations}

APAP: Acetaminophen; ATF6: Activating transcription factor 6;

ATGs: Autophagy-regulated genes; Bort: Bortezomib; ChIP: Chromatin

immunoprecipitation; CHOP: CCAAT/enhancer-binding protein (C/EBP) homologous protein; CMZ: Chlormethiazole; CYP2E1: Cytochrome P450 E1; DAPI: 4',6-Diamidino-2-phenylindole; DDT: Dichlorodiphenyltrichloroethane; ECACC: European collection of cell cultures; EDTA: Ethylenediaminetetraacetic acid; ER: Endoplasmic reticulum; FACS: Fluorescence-activated cell sorting; GRP78: Glucose-regulated protein 78; H_DCFDA: 2 2.9.2 2',7'-

dichlorodihydrofluorescein diacetate; IRE1: Inositol-requiring enzyme 1; LC3: Light chain 3; NAC: N-acetylcysteine; NASH: Non-alcoholic steatohepatitis; PBS: Phosphate-buffered saline; PERK: PKR-like endoplasmic reticulum kinase; PMSF: Phenylmethylsulphonyl fluoride; ROS: Reactive oxygen species; shRNA: Short hairpin RNA; UPR: Unfolded protein response; XBP1: Xbox binding protein 1.

\section{Competing interests}

The authors declare that they have no competing interests.

\section{Authors' contributions}

TL carried out the construction of the CYP2E1 luciferase reporter and the shRNA engineering, the measurement of ROS levels, the western blot analysis, the luciferase reporter, the chromatin immunoprecipitation, the scratch wound assays, performed statistical analysis and drafted the manuscript. RR contributed to the FACS analysis for the measurement of ROS levels, and the chromatin immunoprecipitation, helped to draft the manuscript and critically revised it. SS performed western blot experiments to address the referees' comments. RG performed the ROS measurements to address the referees' comments. MKD participated in the design of the study, the interpretation of the data, helped to draft the manuscript and critically revised it. CD conceived the study, participated in the design of the experiments, interpreted the data, coordinated the research and drafted the final manuscript. All authors read and approved the final manuscript. 


\section{Acknowledgments}

We thank Dr. Cederbaum for providing the CYP2E1 CDNA and Dr. Iwakawi for supplying the pCAX-HA-2XXBP1deltaDBD9anATG)-Luc-F reporter.

\section{Author details}

${ }^{1}$ School of Pharmacy and Pharmaceutical Sciences, Stopford Building, University of Manchester, Oxford Road, Manchester M13 9PT, UK. ${ }^{2}$ Faculty of Life Sciences, Michael Smith Building, University of Manchester, Oxford Road, Manchester M13 9PT, UK. ${ }^{3}$ School of Environment \& Life Sciences, College of Science \& Technology, Cockcroft Building, University of Salford, The Crescent, Salford M5 4WT, UK.

Received: 4 March 2013 Accepted: 29 October 2013 Published: 8 November 2013

\section{References}

1. Guengerich FP: Cytochrome P450s and other enzymes in drug metabolism and toxicity. AAPS J 2006, 8:E101-E111.

2. Coon MJ: Cytochrome P450: nature's most versatile biological catalyst. Annu Rev Pharmacol Toxicol 2005, 45:1-25.

3. Gonzalez FJ: Role of cytochromes P450 in chemical toxicity and oxidative stress: studies with CYP2E1. Mutat Res 2005, 569:101-110.

4. McFadyen MC, Melvin WT, Murray Gl: Cytochrome P450 enzymes: novel options for cancer therapeutics. Mol Cancer Ther 2004, 3:363-371.

5. Murray Gl: The role of cytochrome P450 in tumour development and progression and its potential in therapy. J Pathol 2000, 192:419-426.

6. Miksys S, Tyndale RF: Brain drug-metabolizing cytochrome P450 enzymes are active in vivo, demonstrated by mechanism-based enzyme inhibition. Neuropsychopharmacology 2009, 34:634-640.

7. Caro AA, Cederbaum Al: Oxidative stress, toxicology, and pharmacology of CYP2E1. Annu Rev Pharmacol Toxicol 2004, 44:27-42

8. Liu LG, Yan H, Yao P, Zhang W, Zou L, Song FF, Li K, Sun XF: CYP2E1dependent hepatotoxicity and oxidative damage after ethanol administration in human primary hepatocytes. World I Gastroenterol 2005, 11:4530-4535.

9. Knockaert L, Fromenty B, Robin MA: Mechanisms of mitochondrial targeting of cytochrome P450 2E1: physiopathological role in liver injury and obesity. FEBS / 2011, 278:4252-4260.

10. Morgan ET: Regulation of cytochrome $\mathrm{p} 450$ by inflammatory mediators: why and how? Drug Metab Dispos 2001, 29:207-212.

11. Cederbaum Al, Yang L, Wang X, Wu D: CYP2E1 sensitizes the liver to LPS- and TNF alpha-induced toxicity via elevated oxidative and nitrosative stress and activation of ASK-1 and JNK mitogen-activated kinases. Int J Hepatol 2012, 2012:582790.

12. Helmig S, Dohrel J, Schneider J: Decreased Cyp2E1 mRNA expression in human leucocytes in patients with fibrotic and inflammatory lung diseases. Int J Mol Med 2010, 26:143-149.

13. Danko IM, Chaschin NA: Association of CYP2E1 gene polymorphism with predisposition to cancer development. Exp Oncol 2005, 27:248-256.

14. Dewaele M, Maes H, Agostinis P: ROS-mediated mechanisms of autophagy stimulation and their relevance in cancer therapy. Autophagy 2010, 6:838-854

15. Scherz-Shouval R, Elazar Z: Regulation of autophagy by ROS: physiology and pathology. Trends Biochem Sci 2011, 36:30-38.

16. Ravikumar B, Sarkar S, Davies JE, Futter M, Garcia-Arencibia M, GreenThompson ZW, Jimenez-Sanchez M, Korolchuk VI, Lichtenberg M, Luo S, Massey DC, Menzies FM, Moreau K, Narayanan U, Renna M, Siddiqi FH, Underwood BR, Winslow AR, Rubinsztein DC: Regulation of mammalian autophagy in physiology and pathophysiology. Physiol Rev 2010, 90:1383-1435.

17. Kim I, Xu W, Reed JC: Cell death and endoplasmic reticulum stress: disease relevance and therapeutic opportunities. Nat Rev Drug Discov 2008, 7:1013-1030

18. Rutkowski DT, Kaufman RJ: A trip to the ER: coping with stress. Trends Cell Biol 2004, 14:20-28.

19. Vaclavikova R, Hubackova M, Stribrna-Sarmanova J, Kodet R, Mrhalova M, Novotny JAN, Gut I, Soucek P: RNA expression of cytochrome P450 in breast cancer patients. Anticancer Res 2007, 27:4443-4450.

20. Lacroix M, Toillon RA, Leclercq G: p53 and breast cancer, an update. Endocr Relat Cancer 2006, 13:293-325.
21. Lewis MD, Roberts BJ: Role of CYP2E1 activity in endoplasmic reticulum ubiquitination, proteasome association, and the unfolded protein response. Arch Biochem Biophys 2005, 436:237-245.

22. Xenaki G, Ontikatze T, Rajendran R, Stratford IJ, Dive C, Krstic-Demonacos M, Demonacos C: PCAF is an HIF-1 [alpha] cofactor that regulates p53 transcriptional activity in hypoxia. Oncogene 2008, 27:5785-5796.

23. Andreou K, Rajendran R, Krstic-Demonacos M, Demonacos C: Regulation of CXCR4 gene expression in breast cancer cells under diverse stress conditions. Int J Oncol 2012, 41:2253-2259.

24. Iwawaki T, Akai R: Analysis of the XBP1 splicing mechanism using endoplasmic reticulum stress-indicators. Biochem Biophys Res Comm 2006, 350:709-715.

25. Cory G: Scratch-wound assay. Methods Mol Biol 2011, 769:25-30.

26. Hodges NJ, Green RM, Chipman JK, Graham M: Induction of DNA strand breaks and oxidative stress in HeLa cells by ethanol is dependent on CYP2E1 expression. Mutagenesis 2007, 22:189-194.

27. Klaunig JE, Wang Z, Pu X, Zhou S: Oxidative stress and oxidative damage in chemical carcinogenesis. Toxicol Appl Pharmacol 2011, 254:86-99.

28. Hirose Y, Naito Z, Kato S, Onda M, Sugisaki Y: Immunohistochemical study of CYP2E1 in hepatocellular carcinoma carcinogenesis: examination with newly prepared anti-human CYP2E1 antibody. J Nippon Med Sch 2002, 69:243-251.

29. Kang JS, Wanibuchi H, Morimura K, Gonzalez FJ, Fukushima S: Role of CYP2E1 in diethylnitrosamine-induced hepatocarcinogenesis in vivo. Cancer Res 2007, 67:11141-11146.

30. Kawashiro T, Yamashita K, Zhao XJ, Koyama E, Tani M, Chiba K, Ishizaki T: A study on the metabolism of etoposide and possible interactions with antitumor or supporting agents by human liver microsomes. J Pharmacol Exp Ther 1998, 286:1294-1300.

31. Cederbaum A: Nrf2 and antioxidant defense against CYP2E1 toxicity. Expert Opin Drug Metab Toxicol 2009, 5:1223-1244.

32. Knockaert L, Descatoire V, Vadrot N, Fromenty B, Robin MA: Mitochondrial CYP2E1 is sufficient to mediate oxidative stress and cytotoxicity induced by ethanol and acetaminophen. Toxicol In Vitro 2011, 25:475-484.

33. Kovacic $P$, Somanathan R: Recent developments in the mechanism of anticancer agents based on electron transfer, reactive oxygen species and oxidative stress. Anticancer Agents Med Chem 2011, 11:658-668.

34. Lu W, Ogasawara MA, Huang P: Models of reactive oxygen species in cancer. Drug Discov Today Dis Models 2007, 4:67-73.

35. Malhotra JD, Kaufman RJ: Endoplasmic reticulum stress and oxidative stress: a vicious cycle or a double-edged sword? Antioxid Redox Signal 2007, 9:2277-2293.

36. Nijholt DA, de Graaf TR, van Haastert ES, Oliveira AO, Berkers CR, Zwart $R$, Ovaa H, Baas F, Hoozemans JJ, Scheper W: Endoplasmic reticulum stress activates autophagy but not the proteasome in neuronal cells: implications for Alzheimer's disease. Cell Death Differ 2011, 18:1071-1081.

37. Scheper W, Nijholt DA, Hoozemans JJ: The unfolded protein response and proteostasis in Alzheimer disease: preferential activation of autophagy by endoplasmic reticulum stress. Autophagy 2011, 7:910-911.

38. Droge W: Free radicals in the physiological control of cell function. Physiol Rev 2002, 82:47-95.

39. Nishikawa M: Reactive oxygen species in tumor metastasis. Cancer Lett 2008, 266:53-59.

40. Das J, Ghosh J, Manna P, Sil PC: Acetaminophen induced acute liver failure via oxidative stress and JNK activation: protective role of taurine by the suppression of cytochrome P450 2E1. Free Radic Res 2010, 44:340-355.

41. Hu Y, Mishin V, Johansson I, von Bahr C, Cross A, Ronis MJ, Badger TM, Ingelman-Sundberg M: Chlormethiazole as an efficient inhibitor of cytochrome P450 2E1 expression in rat liver. J Pharmacol Exp Ther 1994, 269:1286-1291.

42. Liu Y, Ye Y: Proteostasis regulation at the endoplasmic reticulum: a new perturbation site for targeted cancer therapy. Cell Res 2011, 21:867-883.

43. Lu Y, Cederbaum Al: CYP2E1 and oxidative liver injury by alcohol. Free Radic Biol Med 2008, 44:723-738.

44. Horn HF, Vousden KH: Coping with stress: multiple ways to activate p53. Oncogene 2007, 26:1306-1316.

45. Oyama T, Morita M, Isse T, Kagawa N, Nakata S, So T, Mizukami M, Ichiki Y, Ono K, Sugaya M, Uramoto H, Yoshimatsu T, Hanagiri T, Sugio K, Kawamoto T, Yasumoto K: Immunohistochemical evaluation of cytochrome P450 (CYP) and p53 in breast cancer. Front Biosci 2005, 10:1156-1161. 
46. Liu B, Chen Y, St Clair DK: ROS and p53: a versatile partnership. Free Radic Biol Med 2008, 44:1529-1535.

47. Kapucuoglu N, Coban T, Raunio H, Pelkonen O, Edwards RJ, Boobis AR, Iscan M: Immunohistochemical demonstration of the expression of CYP2E1 in human breast tumour and non-tumour tissues. Cancer Lett 2003, 196:153-159.

48. Tan M, Li S, Swaroop M, Guan K, Oberley LW, Sun Y: Transcriptional activation of the human glutathione peroxidase promoter by p53. $J \mathrm{Biol}$ Chem 1999, 274:12061-12066.

49. Hu CA, Lin WW, Valle D: Cloning, characterization, and expression of cDNAs encoding human delta 1-pyrroline-5-carboxylate dehydrogenase. J Biol Chem 1996, 271:9795-9800.

50. Sablina AA, Budanov AV, Ilyinskaya GV, Agapova LS, Kravchenko JE, Chumakov PM: The antioxidant function of the p53 tumor suppressor. Nat Med 2005, 11:1306-1313.

51. Matoba S, Kang J-G, Patino WD, Wragg A, Boehm M, Gavrilova O, Hurley PJ, Bunz F, Hwang PM: p53 regulates mitochondrial respiration. Science 2006, 312:1650-1653.

52. Bensaad K, Tsuruta A, Selak MA, Vidal MNC, Nakano K, Bartrons R, Gottlieb E, Vousden KH: TIGAR, a p53-inducible regulator of glycolysis and apoptosis. Cell 2006, 126:107-120.

53. Kondoh H, Lleonart ME, Gil J, Wang J, Degan P, Peters G, Martinez D, Carnero A, Beach D: Glycolytic enzymes can modulate cellular life span. Cancer Res 2005, 65:177-185.

54. Venot C, Maratrat M, Dureuil C, Conseiller E, Bracco L, Debussche L: The requirement for the $\mathrm{p} 53$ proline-rich functional domain for mediation of apoptosis is correlated with specific PIG3 gene transactivation and with transcriptional repression. EMBO J 1998, 17:4668-4679.

55. Trinei M, Giorgio M, Cicalese A, Barozzi S, Ventura A, Migliaccio E, Milia E, Padura IM, Raker VA, Maccarana M, Petronilli V, Minucci S, Bernardi P, Lanfrancone L, Pelicci PG: A p53-p66Shc signalling pathway controls intracellular redox status, levels of oxidation-damaged DNA and oxidative stress-induced apoptosis. Oncogene 2002, 21:3872-3878.

56. Liu Z, Lu H, Shi H, Du Y, Yu J, Gu S, Chen X, Liu KJ, Hu CA: PUMA overexpression induces reactive oxygen species generation and proteasome-mediated stathmin degradation in colorectal cancer cells. Cancer Res 2005, 65:1647-1654.

57. Szak ST, Mays D, Pietenpol JA: Kinetics of p53 binding to promoter sites in vivo. Mol Cell Biol 2001, 21:3375-3386.

58. Campomenosi P, Monti P, Aprile A, Abbondandolo A, Frebourg T, Gold B, Crook T, Inga A, Resnick MA, Iggo R, Fronza G: p53 mutants can often transactivate promoters containing a p21 but not Bax or PIG3 responsive elements. Oncogene 2001, 20:3573-3579.

59. Rajendran R, Garva R, Ashour H, Leung T, Stratford I, Krstic-Demonacos M, Demonacos C: Acetylation mediated by the p300/CBP-associated factor determines cellular energy metabolic pathways in cancer. Int J Oncol 2013, 42:1961-1972.

60. Liu B, Cheng Y, Liu Q, Bao JK, Yang JM: Autophagic pathways as new targets for cancer drug development. Acta Pharmacol Sin 2010, 31:1154-1164

61. Clarke R, Cook KL, Hu R, Facey CO, Tavassoly I, Schwartz JL, Baumann WT, Tyson JJ, Xuan J, Wang Y, Wärri A, Shajahan AN: Endoplasmic reticulum stress, the unfolded protein response, autophagy, and the integrated regulation of breast cancer cell fate. Cancer Res 2012, 72:1321-1331.

62. Tasdemir E, Maiuri MC, Galluzzi L, Vitale I, Djavaheri-Mergny M, D'Amelio M, Criollo A, Morselli E, Zhu C, Harper F, Nannmark U, Samara C, Pinton P, Vicencio JM, Carnuccio R, Moll UM, Madeo F, Paterlini-Brechot P, Rizzuto R, Szabadkai G, Pierron G, Blomgren K, Tavernarakis N, Codogno P, Cecconi F, Kroemer G: Regulation of autophagy by cytoplasmic p53. Nat Cell Biol 2008, 10:676-687.

63. Pietrocola F, Izzo V, Niso-Santano M, Vacchelli E, Galluzzi L, Maiuri MC, Kroemer G: Regulation of autophagy by stress-responsive transcription factors. Semin Cancer Biol 2013, 23:310-322.

64. Maiuri MC, Galluzzi L, Morselli E, Kepp O, Malik SA, Kroemer G: Autophagy regulation by p53. Curr Opin Cell Biol 2010, 22:181-185.

65. Lieber CS: Cytochrome P-4502E1: its physiological and pathological role. Physiol Rev 1997, 77:517-544.

66. Qu L, Huang S, Baltzis D, Rivas-Estilla AM, Pluquet O, Hatzoglou M, Koumenis C, Taya Y, Yoshimura A, Koromilas AE: Endoplasmic reticulum stress induces p53 cytoplasmic localization and prevents p53-dependent apoptosis by a pathway involving glycogen synthase kinase-3beta. Genes Dev 2004, 18:261-277.

67. Zhang F, Hamanaka RB, Bobrovnikova-Marjon E, Gordan JD, Dai MS, Lu H, Simon MC, Diehl JA: Ribosomal stress couples the unfolded protein response to p53-dependent cell cycle arrest. J Biol Chem 2006, 281:30036-30045.

68. Lin WC, Chuang YC, Chang YS, Lai MD, Teng YN, Su IJ, Wang CC, Lee KH, Hung JH: Endoplasmic reticulum stress stimulates p53 expression through NF-kappaB activation. PLoS One 2012, 7:e39120.

69. Hickling KC, Hitchcock JM, Oreffo V, Mally A, Hammond TG, Evans JG, Chipman JK: Evidence of oxidative stress and associated DNA damage, increased proliferative drive, and altered gene expression in rat liver produced by the cholangiocarcinogenic agent furan. Toxicol Pathol 2010 38:230-243

70. Dey A, Kessova IG, Cederbaum Al: Decreased protein and mRNA expression of ER stress proteins GRP78 and GRP94 in HepG2 cells over-expressing CYP2E1. Arch Biochem Biophys 2006, 447:155-166.

71. Luo B, Lee AS: The critical roles of endoplasmic reticulum chaperones and unfolded protein response in tumorigenesis and anticancer therapies. Oncogene 2013, 32:805-818.

72. Chang JT, Chang GC, Ko JL, Liao HY, Liu HJ, Chen CC, Su JM, Lee H, Sheu GT: Induction of tubulin by docetaxel is associated with p53 status in human non small cell lung cancer cell lines. Int J Cancer 2006, 118:317-325.

73. Rouzier R, Rajan R, Wagner P, Hess KR, Gold DL, Stec J, Ayers M, Ross JS, Zhang P, Buchholz TA, Kuerer H, Green M, Arun B, Hortobagyi GN, Symmans WF, Pusztai L: Microtubule-associated protein tau: a marker of paclitaxel sensitivity in breast cancer. Proc Natl Acad Sci U S A 2005, 102:8315-8320.

74. Ikeda H, Taira N, Hara F, Fujita T, Yamamoto H, Soh J, Toyooka S, Nogami T, Shien T, Doihara H, Miyoshi S: The estrogen receptor influences microtubule-associated protein tau (MAPT) expression and the selective estrogen receptor inhibitor fulvestrant downregulates MAPT and increases the sensitivity to taxane in breast cancer cells. Breast Cancer Res 2010, 12:R43.

75. Matrone MA, Whipple RA, Thompson K, Cho EH, Vitolo Ml, Balzer EM, Yoon JR, loffe OB, Tuttle KC, Tan M, Martin SS: Metastatic breast tumors express increased tau, which promotes microtentacle formation and the reattachment of detached breast tumor cells. Oncogene 2010, 29:3217-3227.

76. Baraz L, Haupt Y, Elkin M, Peretz T, Vlodavsky I: Tumor suppressor p53 regulates heparanase gene expression. Oncogene 2006, 25:3939-3947.

77. Li Y, Liu H, Huang YY, Pu LJ, Zhang XD, Jiang CC, Jiang ZW: Suppression of endoplasmic reticulum stress-induced invasion and migration of breast cancer cells through the downregulation of heparanase. Int J Mol Med 2013, 31:1234-1242.

78. Kim DK, Kim YH, Jang HH, Park J, Kim JR, Koh M, Jeong WI, Koo SH, Park TS, Yun CH, Park SB, Chiang JYL, Lee CH, Choi HS: Estrogen-related receptor gamma controls hepatic CB1 receptor-mediated CYP2E1 expression and oxidative liver injury by alcohol. Gut 2013, 62:1044-1054.

79. Wong AW, Paulson QX, Hong J, Stubbins RE, Poh K, Schrader E, Nunez NP: Alcohol promotes breast cancer cell invasion by regulating the Nm23-ITGA5 pathway. J Exp Clin Cancer Res: CR 2011, 30:75.

\section{doi:10.1186/bcr3574}

Cite this article as: Leung et al:: Cytochrome P450 2E1 (CYP2E1) regulates the response to oxidative stress and migration of breast cancer cells. Breast Cancer Research 2013 15:R107. 